\title{
Macro and Micro Characterization of Biopolymers: Case of Cotton Fibre
}

\author{
Omar Harzallah and Jean-Yves Drean \\ Laboratoire de Physique et Mécanique Textiles EAC 7189 CNRS, \\ Université de Haute Alsace, \\ France
}

\section{Introduction}

This chapter's aim is to give the reader an overview of different methods used to characterise biopolymers based on the case of cotton fibre. It is not meant to be an exhaustive list of methods, but to give examples that illustrate as clearly as possible the most used and most efficient methods.

The cotton fibre is a very complex biopolymer whose properties depend on varietal and environmental conditions. Cotton fibre is a very well adapted example to describe the different methods to characterise the morphology, the mechanical properties on single fibres or on fibre bundles and the surface properties.

Reference methods are described as well as more advanced methods based on experiments which have been carried out by the authors and their co-workers.

\section{Development of cotton fibre}

\subsection{Origin of cotton}

The Cotton plant belongs to the order of Malvales, the family Malvaceae, the tribe Hibiscus, and the genus Gossypium. There are four domesticated species of cotton of commercial importance: G. barbadense, G. hirsutum, G. arboreum and G. herbaceum. Each one of these commercially important species contains many different varieties developed through breeding programmes to produce various types of cotton with continually improving properties such as faster maturing, improved insect and disease resistance, greater length, better strength and uniformity.

At various periods, the $G$. barbadense $L$, native South America, was transported to various parts of the world and grown as a commercial crop. Breeding and selection in this species resulted in varieties known for their superior fibre quality. These belong to the long staple varieties of cotton and are known for their length exceeding $33 \mathrm{~mm}$, fine fibres with exceptional tensile strength. They supply about $8 \%$ of the current world production of cotton fibre. This group includes the commercial varieties of Egyptian, Sea Island, and Pima cottons.

G. hirsutum L., which produces medium to long fibres ( $25 \mathrm{~mm}$ to $32 \mathrm{~mm}$ ), is developed in the United States from cotton native to Mexico and Central America and includes all the many commercial varieties of American Upland cotton. Upland cotton, now provides over $90 \%$ of the world production of raw cotton fibre. Fibre from $G$. hirsutum $L$ is widely used in apparel, 
home furnishing and industrial products. G. barbadense $L$ Pima is used for the production of high-quality fabrics.

The other species, $G$. arboreum $L$. and $G$. herbaceum $L$ are the shortest staple types of cotton cultivated (inferior to $25 \mathrm{~mm}$ ) and are coarse. Both are of minor commercial importance worldwide but are still grown commercially in Pakistan and India.

According to projections by the International Cotton Advisory Committee (ICAC), world cotton production is expected to grow by nearly $10 \%$ in $2010 / 11$ upto 24.2 million tons, against 22.2 Mt in 2009/10. The main cotton producers are China (31\%), India (23\%), the United States (12\%), Pakistan (10\%) and Brazil with 5\% of world production.

\subsection{Morphology}

The cotton plant has a branched taproot capable of going down to several meters below the ground surface in optimum conditions. This root part has the dual role of supporting the plant and absorbing nutrients from the soil.

The sowing date of cotton seed is determined by climatic conditions (temperature, rainfall). It varies from one region to another and may extend over several seasons depending on climate.

According to varietal and environmental conditions, the phase of emergence (10 to 30 days from germination to the spreading of the cotyledons) as well as the plantlet stage last about 50 to 65 days. They are followed by anthesis announcing the end of the vegetative phase and the beginning of the flowering phase. The rate of flowering can vary after the varietal and climatic conditions. Pollination occurs in the few hours after the opening of flowers, fertilization is completed within thirty hours after the opening of the flower. Certain ovules may not be fertilized, others may abort despite normal fertilization. These are the causes of aborted seeds, usually called dead.

Flowering is spread over time, the phases of flowering and maturation overlap. The maturation phase of the capsules (fruits of cotton) may last 40 to 80 days, or more depending on the variety, growing conditions and position of the capsule in the plant. After this phase, the mature capsules open and the seed cotton is dry. Seed cotton is the subject of the harvesting and is constituted of the seeds and fibres they carry. Flowers can continue their development despite the fact that the first capsules are open. It is a characteristic of the cotton plant to present simultaneously flower buds, flowers, capsules closed or opened during its development.

In the mature stage fibres are constituted of about $95 \%$ of cellulose; other not cellulosic constituents: mineral substances $(1.4 \%)$, wax $(0.9 \%)$, proteins $(1.6 \%)$, pectic acids $(0.9 \%)$ and other organic acids are located in the secondary membrane and in the lumen (Parry, 1982).

\subsection{Cotton fibre structure}

The cotton fibre is unicellular; it develops from the epidermal cell of the ovule (called seed after maturation). Its development begins before the anthesis (Joshi and al, 1967; Lagière, 1966; Parry, 1982) or on the same day of the anthesis (Beasley, 1975; Stewart, 1975). Following flowering, each cell elongates until reaching its final length in about 20 to 25 days. The ultimate length is determined by the cotton variety and environmental conditions. During this growth, the cells are encircled by a primary cell wall (less than $1 \mu \mathrm{m}$ thick) and covered by a wax layer or cuticle (Lewin \& Pearce, 1998). This waxy and smooth layer has a significant impact on the smoothness and the handling of cotton during processing. During this development stage, the fibre begins to be thickened by deposition of regular layers of secondary-wall cellulose inside the primary cell wall (Fig. 1). 


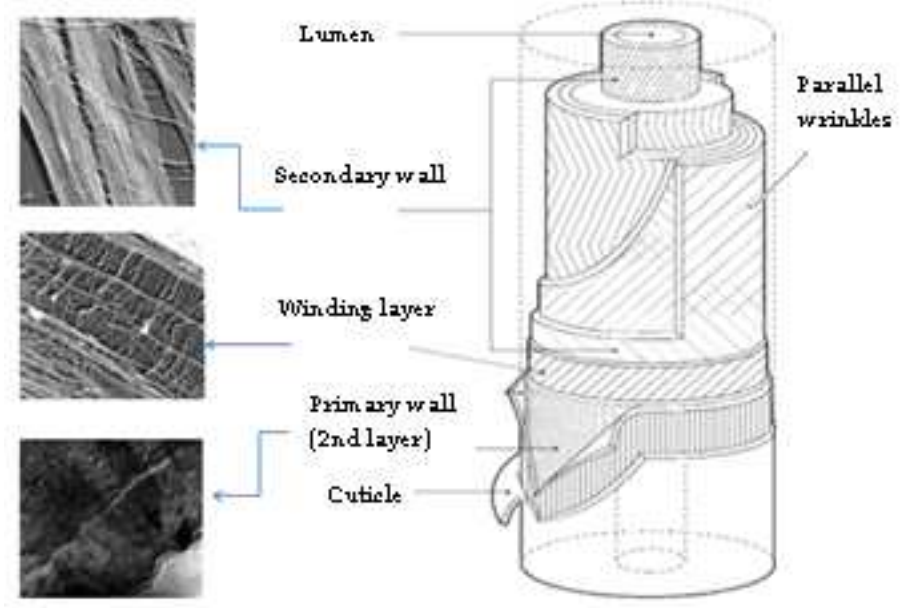

Fig. 1. Fibre structure (Seagull \& Alpspaugh, 2001)

The central layers of the secondary wall are characterised by a thickness (approximately 4 $\mu \mathrm{m}$ thick) that constitutes about $90 \%$ of the weight of the lint (Seagull \& Alpspaugh, 2001) and their structure represents the major portion of the strength of the fibre. Between seven and nine weeks most fibres terminate wall thickening.

Cellulose in the crystalline state begins to form 15-19 days post-anathesis, and by maturity, tubular fibres contain 96\% (Lewin \& Pearce, 1998) of cellulose with $90 \%$ in the secondary wall (Kohel, 1999). Shenai (Shenai, 1988) has shown that strength and elongation increase with the increasing crystalline microfibril spiral arrangement and orientation within the cotton fibres. In fact, the structure contains parallel wrinkles at a slight angle relative to its axis, forming a helical structure. In the winding layer the cellulose microfibrils are aligned at angles ranging $40-70^{\circ}$ relative to the fibre axis, whereas each microfibril in the primary wall spirals at $20-30^{\circ}$ relative to the fibre axis. In the thick secondary wall, the fibrils are approximately oriented at a $45^{\circ}$ angle. The helical orientation can be shown up in various ways: optical birefringence, for direction of the molecule chains measurement; X-ray diffraction, for the axis of the crystal lattice evaluation; electron microscopy, for the microfibrils observation; optical microscopy, for the coarse fibrils observation.

The final stage appends when the boll opening begins at maturity leaving the fibres fully exposed to air and sunlight. The fibre water content rapidly decreases as the cytoplasm dries against the inner surface of the wall. The lumen collapses causing a convoluted surface of the cotton fibre. The fibre assumes a twisted conformation. These twists, or convolutions, make it possible for the fibres to be spun into yarns. If the fibre does not produce a thick secondary wall, the fibre is said to be immature. When such fibres are dried, they form thin, flattened ribbons with minimal twisting. Because fibres begin development at different times, on a mature seed there may be fibres with differing levels of maturity.

An accurate assessment of the degree of maturity is essential since the presence of immature fibres can cause many problems during processing (Thibodeaux \& Rajasekaran, 1999). The reduced strength and resilience of the immature fibre lead to excessive damage and waste at ginning and carding operations. It could also lead to weak and uneven yarns, increase the tendency of fibres to tangle and form neps. In addition, the effect of maturity on the dyestuff 
picking is well known. The Goldthwait test is based on this effect (Goldthwait \& al., 1947). In fact, because of the relative low dye affinity of immature fibre due to low cellulose content, numerous dyeing imperfections could appear in fabrics. These defects are commonly known as white specs (Xu \& Pourdeyhimi, 1994).

The characteristics of the cell wall-thickness which represents the maturity of the fibre are largely environmental (nutrition water supply, temperature, etc...) in nature and may be somewhat modified by varieties. Other important factors are the day of flowering, the beginning and the end of the season. Different places on the seed differ markedly in wall development.

\section{Physical properties of cotton fibres}

\subsection{Cotton fibre maturity}

Maturity is one of the determinants in evaluating cotton quality because it can affect many properties of cotton fibres. Mature fibres usually possess greater strength and better resilience. The presence of immature fibres may cause excessive waste during processing and may weaken yarn strength (Raes \& Verschraege, 1981). Immature fibres have also been recognized as one of the main causes of neps formation in carded webs, yielding a rough and uneven appearance of yarns and fabrics. Due to their relatively low dye affinity (Thibodeaux \& Evans, 1986), neps easily show up as imperfections in a dyed fabric. Hence information about cotton maturity is desirable and essential for cotton growers and processors. The experimental methods of testing cotton maturity can be classified into direct and indirect approaches (Thibodeaux \& Evans, 1986).

\subsubsection{Direct methods}

One direct method is based on microprojection in order to measure the perimeter and area of fibres and lumens, which are subsequently used to calculate maturity. Another method determines the proportion of immature fibres by counting the number of mature fibres present in the sample. This procedure (Brown \& al., 1996) involves using an $18 \%$ solution of sodium hydroxide as the mounting medium to swell the fibres. The swollen fibres are then examined under a microscope at a magnification of 400X. If a fibre is swollen into an unconvoluted and rod-like shape, it can be counted as a mature fibre. The main drawbacks of these methods are low efficiency and accuracy.

\subsubsection{Indirect methods}

Indirect methods are those based on some fibre characteristics that are associated with the degree of wall thickening of the fibre, such as air permeability (Powland \& al., 1976; Raes \& Verschraege, 1981), birefringence and dyeability (ASTM D1464-79). The Micronaire instrument (ASTM D1448-84) measures the resistance to an air flow through a pre-weighed cotton tuft and this method is the most frequently used. Micronaire Index (Mic) represents a combined measure of cotton fineness $\mathrm{H}$ and maturity $\mathrm{M}$ (Lord, 1956). Fibre fineness or coarseness is defined as the weight per unit length or the linear density of the fibre (ASTM D1769-77); expressed in millitex (mtex, micrograms per meter).

The method of measurement carried out by the Advanced Fibre Information System (AFIS) is based on detecting the attenuation of light amount that is diffracted by a fibre. Fibres which are individually transported by a fast air stream, cross a beam of light. The reflected light will be detected by an electro-optical sensor placed at $40^{\circ}$ from the normal direction of the beam (Bragg \& Shofner, 1993). The diffraction signal is related to the shape of the fibre. 
Much research has been conducted with image analysis technology to measure the cotton maturity and other parameters from fibre cross sections (Xu \& al.; 1992; Xu \& al., 1993). The success of a cross sectional method using image analysis largely relies on two techniques i.e. fibre cross sectioning and image segmentation. Cross-sectioning is the most significant step in obtaining analysable images of fibres. A bundle of fibres embedded in a polymer resin is cut (Annis \& al., 1992; Boylston \& al., 1995) and the surface containing the fibre cross sections is imaged on a microscope by reflected light (Annis \& al., 1992). Image segmentation is a computational process that separates cotton cross sections from the image background from one another. Due to variations in the cross sectional shape and thickness of sliced samples, fibres in different regions exhibit different levels of contrast and focus in an image. The image analysis system for processing cotton cross sectional images often requires operator assistance to draw separation lines between touching fibres, to locate lumens, and to connect broken edges.

Therefore, Image Analysis presents a quick and reliable technique for determining the cotton fibre maturity which consists of performing cotton fibre cross-section, acquiring and analyzing their image to determine: Perimeter, Area and Theta (degree of secondary wall thickening of cotton fibres). (Xu \& Huang, 2004)

Figure 2 shows a schematic cross section of the cotton fibre; the shaded area is the secondary cell wall and the linear dimension measured along the outer periphery of the fibre is called the perimeter.

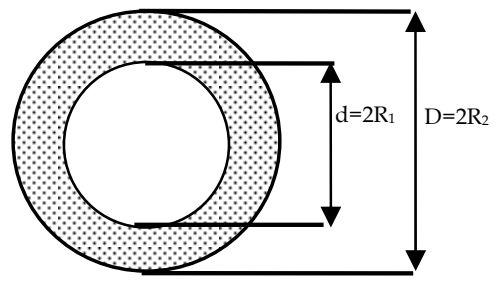

Fig. 2. Schematic cross section of the cotton fibre

From this schematic cross section of the cotton fibre, we can deduce this relationship (equation 1):

$$
A_{w}=\pi\left(R_{2}^{2}-R_{1}^{2}\right)
$$

Where $A_{w}$ is the cell-wall area (cross-sectional area minus lumen area) in microns and respectively, $R_{1}$ and $R_{2}$ is the inside and outside diameter. Since the degree of thickening (Theta) was defined as the ratio of the cross sectional area of the total fibre wall to the area of a circle of the same perimeter (equation 2). Then:

$$
\theta=\frac{\pi\left(R_{2}^{2}-R_{1}^{2}\right)}{\pi R_{2}^{2}}=\frac{A_{w}}{\pi R_{2}^{2}}=\frac{A_{w}}{\pi\left(\frac{P_{2}}{2 \pi}\right)^{2}}=\frac{4 \pi A_{w}}{P_{2}^{2}}
$$

Where $\theta$ is equal to the degree of secondary wall thickening (no unit) and $P_{2}$ is the outside perimeter of the fibre expressed in microns. 
Completely circular fibres, regardless of their perimeter, have a value of theta equal to unity (based on completely round and solid cross sections). Mature fibres typically have kidney bean shaped cross sections and a high theta value. Immature fibres, which collapse to a greater extent upon boll opening, have lower theta value.

\subsubsection{Results}

The authors of this chapter conducted experiments (Harzallah \& al., 2010) based on the image analysis method to characterise four types of cotton (Figs. 3a to 3d), which were selected based on their distinct physical properties, and compared the results obtained with AFIS measurements. These types of cotton consisted in Upland varieties from the 2003 harvest. The method principle is based on measuring the fibre perimeter $(\mathrm{P})$ and cross sectional area (S) to calculate the degree of secondary wall thickening of cotton fibres (Fig.4).

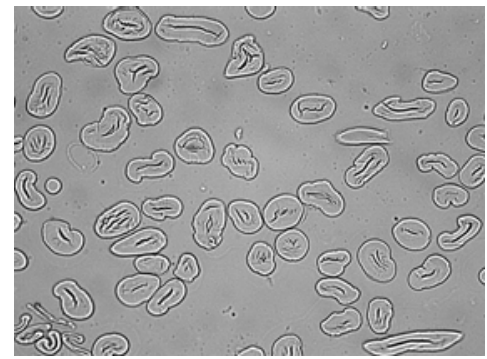

Fig. 3a. Microscopic observation for the section of the cotton I (X 400)

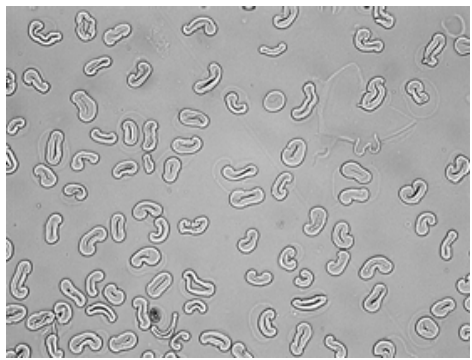

Fig. 3b. Microscopic observation for the section of the cotton II (X 400)

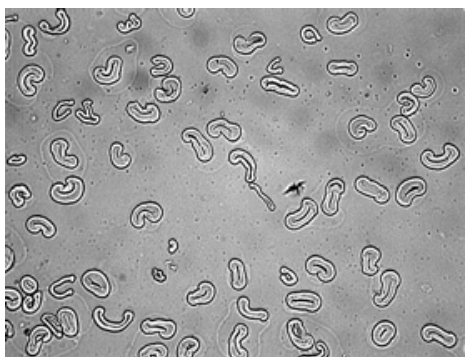

Fig. 3c. Microscopic observation for the section of the cotton III (X 400) 


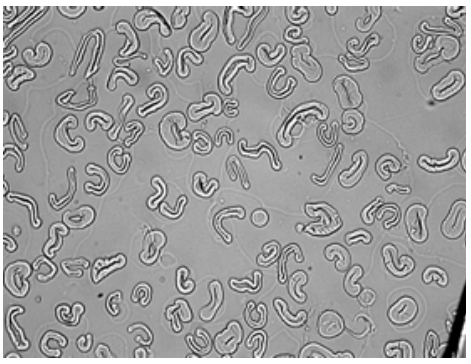

Fig. 3d. Microscopic observation for the section of the cotton IV (X 400)

Authors note that no significant difference was observed for cotton III and IV, while for cotton I and II, there have been slight differences in the determination of the maturity ratio. These differences have been attributed to the high degree of irregularity of the cross sectional shape of fibres. Indeed, despite the large number of cross sections studied $(\approx 1500)$, with the image analysis method, the lowest CV for theta parameter is $19 \%$ and the highest is $40 \%$, while the highest CV noted with AFIS measurement is $2.63 \%$. The results obtained are in accordance with Huang and al. results (Huang \& Xu, 2002) that show a good correlation between the AFIS data and the Image Analysis results, especially for the perimeter.

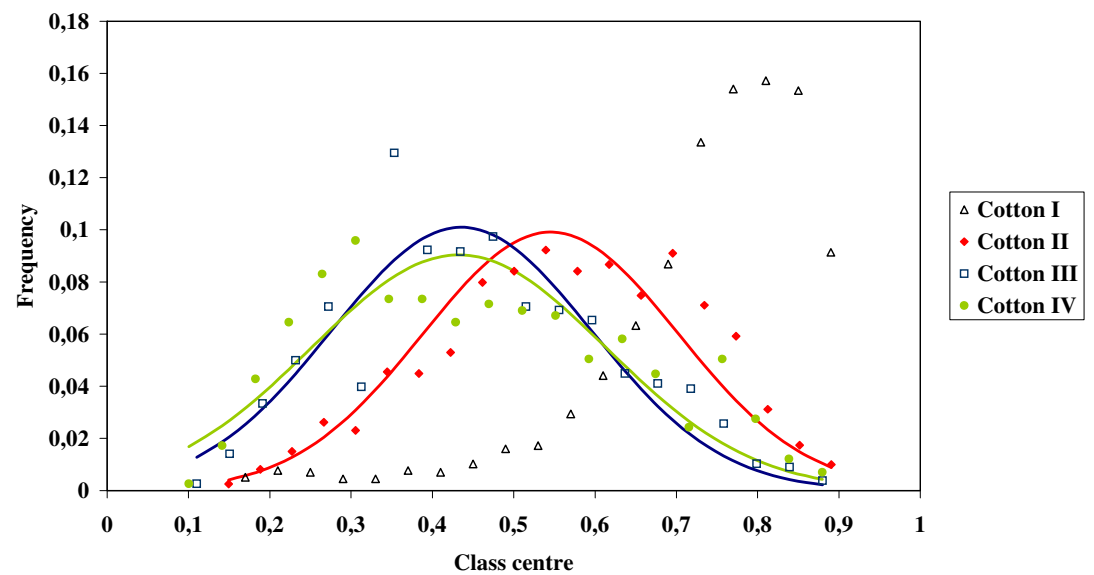

Fig. 4. Theta distribution for the four types of cotton

\subsection{Fibre-length measurement}

Some techniques have been proposed for measuring the fibre length, such as the Sutterwebb Array, ALmeter, AFIS (Advanced Fibre Information System) and HVI (High Volume Instrument) methods. In general, obtaining samples from the fibre population has been carried out in two different ways. One is the numerical sampling method, in which each length in the sample is proportional to the corresponding number of fibres in the overall population. The other is the length or weight biased sampling method, in which the number of fibres of each length is proportional to the total length or weight of these fibres. Also, two different methods of measurement are used, the numerical and weight biased methods. 


\subsubsection{Reference method}

The reference method is a method where the length of every group of fibre is measured and allows a histogram to be plotted from which the average, the coefficient of variation and others statistical parameters are deducted.

In this paragraph, we will describe the Zweigle sorter method. This method is based on using a Johannsen-Zweigle apparatus consisting of two steel comb fields which allow to straighten and align the fibres. For cotton, the comb spacing is $4 \mathrm{~mm}$. Here the weight of the test specimen is $100 \mathrm{mg}$. The weighed sample is prepared by one of the zoning methods (Morton \& Hearle, 2008). Then, by repeated drawing and doubling, it is formed into a narrow bundle of fibres, which are straight and parallel as possible.

The aim of this method is to sort the fibres into groups of predetermined length intervals by using the special tweezers. The fibres of each group are then weighed to obtain a mass distribution for the sample. In this procedure, each group's length interval is determined by the spacing of the combs, which must therefore be such as to provide at least ten groups from the sample of material under examination and must extend over at least the length of the longest fibre. So, the longest fibres are pulled and weighed first and then the shortest. The time taken by an experienced worker in making a single Zweigle sorter test, excluding sampling and analyzing of data, ranges from about $3 / 4$ hour for a short-stapled Indian cotton to $1 \frac{1 / 2}{2}$ hours for long stapled Egyptian or Sea Island Cotton.

\subsubsection{Capacitance scanning}

Peyer Texlab System, which was introduced in the 1960s, is based on the same measurement method and is still currently used. This apparatus is composed of two systems which sort and align a fibre beard and measure its length distribution. The Fibroliner (FL-101) mechanically combs either sliver or ginned lint specimens into a parallel beard. The straight and aligned fibres are placed between a pair of carrier films for measurements. The ALmeter (AL-101) scans the beard using capacitance measurements to produce an output signal that is proportional to the cumulative mass distribution. The capacitor scans the fibres of the test specimen every $0.125 \mathrm{~mm}$. The microprocessor can convert the mass distribution to a number distribution when the linear density of the fibres is assumed to be constant.

The ALmeter test can be performed in approximately 15 minutes, while it takes about two hours to make the Zweigle sorter test. The ALmeter can supply different sets of array information from the raw data, including a weight based distribution, an area based distribution and a Fibrograph. From these distributions parametric values such as the mean length biased by cross-section, mean length biased by weight, coefficients of variation and other useful statistical parameters can be extracted.

\subsubsection{Photo-electric scanning method}

The original idea of the photoelectric scanning or Fibrograph method (ASTM D1447-83) has been developed by Hertel in 1940 for testing cotton lint (Hertel, 1940). This test method covers the measurement of the length and length uniformity of cotton fibres. By using the fibrosamplers, beard of fibres are randomly caught on combs to obtain an equal probability of selecting any given fibre length. The beard formed by the captured fibres is scanned photoelectrically from base to tip (no more fibres). The amount of light passing through the beard is a measure of the number of fibres that extend various distances from the combs. In the early 1980s, a fast fibre testing system called high volume instruments (HVI) was developed. This system is now produced by Uster Technologies to test a number of key fibre 
properties including fibre length (ASTM D4605-86). This apparatus uses automatic preparation to ensure that all points along the length of each fibre have an equal chance of coinciding with the line of the comb teeth. The fibres clamped in this comb are then combed and brushed to form a fibre beard of parallel and straight fibres. Then an automatic feeding of fringes through photoelectric sensing is realized. When the fibre beard is analyzed, the HVI measures the fibre length based on the Fibrograph method.

The auto-sampling has increased the rapidity of the preparation for analysis. With the original Fibrograph, the time required to make a complete test, including preparation of the beard and analysis of the Fibrogram (Fig. 5), is about 10 minutes. In the automated HVI tests, the analysis is computerized and testing takes only few minutes.

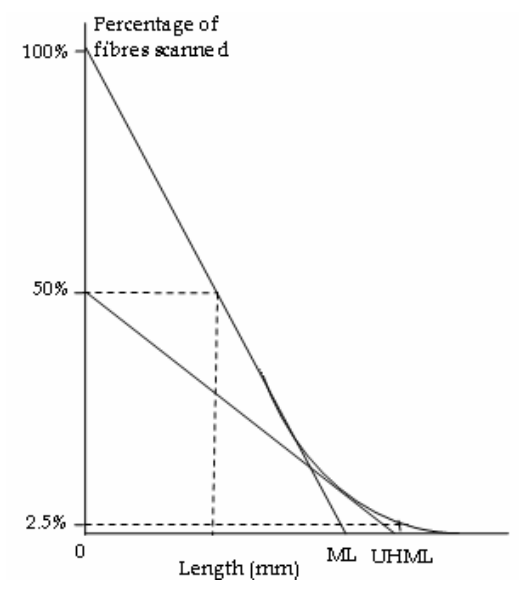

Fig. 5. a Fibrogram

There are two interpretation systems for the Fibrogram: Span length (SL) or Mean Length (ML). The $\mathrm{x} \%$ SL was defined as being the length exceeded by only $\mathrm{x} \%$ of the beard fibres scanned by the instrument. The commercial practices have retained the $50 \% \mathrm{SL}$ and the $2.5 \%$ SL. The $50 \%$ SL represents an approximation of the average length of the fibres scanned, while the $2.5 \%$ SL was used as commercial length. Until 1995, the standard ICCS (International Standard Calibration Cotton) gave the lengths according to this interpretation of the Fibrogram.

The interpretation system by "Mean Lengths" is graphically equivalent to the tracing of tangents to the Fibrogram tuft at characteristic points. Mean length (ML) is obtained by drawing a tangent to the Fibrogram from the $100 \%$ point of fibres and extrapolating to the lengths axis (Figure 5). This value represents the average length of all fibres constituting the beard (Equation 3).

$$
\text { Mean length }=\frac{\sum_{n_{i} \%=0}^{100} n_{i} \% \cdot \ell_{i}}{\sum_{n_{i} \%=0}^{100} n_{i} \%}
$$

Where $n_{i} \%$ is the percentage of fibres of length $\ell_{i}$. 
The tangent to the Fibrograph drawn from the $50 \%$ point of fibres and extrapolating to the lengths axis indicates the Upper Half Mean length (UHML) which indicates the average length of the longer half of the fibres (Equation 4).

$$
\text { Upper Half Mean length }=\frac{\sum_{n_{i} \%=0}^{50} n_{i} \% \cdot \ell_{i}}{\sum_{n_{i} \%=0}^{50} n_{i} \%}
$$

Where $n_{i} \%$ is the percentage of fibres of length $\ell_{i}$.

Ratios of uniformity are deducted from both systems of interpretation of the Fibrograph. Uniformity Index (UI \%) is the ratio of the mean length ML to the upper half mean length UHML. It is a measure of the uniformity of fibre lengths in the sample expressed as a percent. It is typically just above 0.8 in HVIs and 0.7 in comb sorters. On the other hand, Uniformity Ratio (UR \%) is determined by dividing the $50 \%$ span length by the $2.5 \%$ span length and expressed as a percentage. It is a smaller value than the uniformity index by a factor close to 1.8. Larger values indicate a more uniform fibre length distribution, while lower values tend to be associated with manufacturing waste, more difficult processing, and lower the product quality. The uniformity index (or the uniformity ratio) represents the most commonly used shape parameter of the length distribution. The Fibrograph uses the theory of Span Lengths while the HVI, further to recent decisions of standardization, uses the system of Mean Lengths.

\section{Mechanical properties}

\subsection{Bundle fibre testing}

Before studying the measuring methods, let us see the definition of the tenacity, the notion appropriate for the domain of the fibres science and fundamentally different from the measurable variable "tenacity" used in the mechanics of materials. The tenacity in the textile domain, expressed as $\mathrm{cN} /$ tex, can be linked through the density to the stress notion in tensile test generally used for materials (Equation 5).

$$
\text { Tenacity }(c N / \text { tex })=\frac{\text { stress }(P a) \times 10^{-4}}{\text { density }\left(\mathrm{Kg} / \mathrm{m}^{3}\right)}=\frac{F_{\text {at break }}(\mathrm{cN})}{\text { linear density }(\text { tex })}
$$

The stress corresponds to the break load by unit of the breakage surface, generally expressed in Pascal or daN $/ \mathrm{cm}^{2}$. As it is not possible to measure the surface broken for textile materials, the mass per unit length $(\mathrm{g} / 1000 \mathrm{~m})$ is used which is a correct estimation when the density of materials is constant and known ; it is known that the density of the cellulose is $1.52 \mathrm{~g} / \mathrm{cm}^{3}$ (Morton \& Hearle, 1975). The assumption of homogeneity of density appears to us debatable for the following reasons. First the area of the broken section can be different from the mean value estimated by a mean value of the fineness. The second reason is assigned to the differences of the structure organization in the diverse layers which compose the fibres and lead probably to the density variation. The mass per unit length and the density would not, then, be equivalent in both main layers of cotton fibres. In 1999, Kunzel and al. mentioned several literature references on the subject. 
The internal structure is composed of fibrils which can be bound on different lengths between them by a more or less important number of connections. It conditions then the recorded strengths of break. This different organization of fibrils according to the layer of the considered fibre (primary or secondary wall) would generate the effect of modifying the acceptable stresses of the various layers. The applicable stress on the fibre would be thus dependent on the proportion between the areas of both main walls, in other words on the maturity of the considered fibre. These differences would lead then to the significant difference of the tenacity according to the type of fibres tested on tensile test. Earlier systems of testing include: the Pressley and the Stelometer tester.

\subsubsection{Stelometer tester}

In 1953, the stelometer was created by Hertel (Hertel, 1953) in order to avoid certain inconveniences of the existing devices of that period, more particularly Pressley (Pressley, 42). Indeed, the stelometer is the first device with constant rate of load allowing the measure of the elongation thanks to the dynamometric test with a $1 / 8$ inch or $3.175 \mathrm{~mm}$ gauge metal spacer between the clamps (called Pressley clamps). The use of particular devices for specimen preparation, the application of a pre-tension to the fibres before the test and the possibility of measuring the fibres elongation made the stelometer a reference in the tenacity characterization (ASTM D1445-75).

\subsubsection{High volume instruments ( $\mathrm{HVI})$}

The principle of the HVIs is largely based on the Stelometer arrangement. HVI strength tests were calibrated against the 1/8-in. gauge Pressley measurement. A tapered specimen in which the fibres are randomly clamped along their lengths is used. The free ends of fibres are combed in preparation for being tested. When a fibre beard is analyzed, the HVI first measures the fibre length with the Fibrograph method. Then, the comb is moved so that the desired "break amount" of fibre is positioned over the leading edge of the rear jaw. The jaw clamps the beard; and the breaker step motor rotates, causing the rear jaws to move at a constant rate. This rate is estimated at 0.14 inches/second for the Spinlab model. Force and displacement voltage signals are recorded at every second step of the breaker step motor. The fibre bundle strength and elongation data are usually reported together (ASTM D4605-86). The HVI bundle-strength measurements are reported in grams-force/tex. In the HVI, the fibre bundle cannot be weighed. Indirect measurements of linear density such as light attenuation were used. In fact, the light from a LED (Light Emitting Diode) source crosses the fibre beard to a detector and is converted into a voltage that is proportional to the beard mass at that position.

All earliest studies were concentrated on how to measure tensile strength using the HVI and to explain the results obtained. Previous work has demonstrated that the following factors affect the HVI measurement method and its precision. Sample conditioning history and the sampling methods affect the strength measurements; the fibre strength increases nearly $10 \%$ for a $1 \%$ increase in moisture (Lawson \& al., 1976). The mechanisms and procedures to prepare cotton for tenacity testing, the tapering of fibres near their ends, the residual crimp after brushing were studied by Taylor (Taylor, 1986). The light crossing the fibres and the amount of light reaching the detector seem to affect the beard mass. Optical density (Landstreet \& al., 1989) and micronaire (Taylor \& al., 1991) are used to evaluate the mass of the sample being broken but surface characteristics such as fibre surface irregularities; moisture content and colour affect the optical reading. 
The authors of this chapter with the help of Hequet's team (Fiber and Biopolymer Research Institute, Lubbock, TX - USA) have conducted a work (Benzina \& al., 2007) to attempt to calibrate the high volume instrument elongation measurements. This study found that the negative correlation between fibre tenacity and elongation measured with HVI instruments was weak and it was possible to have different types of cotton with good tenacity and elongation. The bundle elongation and tenacity of cotton fibres were measured using a modified tensile testing instrument to which Pressley clamps (1/8 inch gage length) were adapted. Work of rupture were correlated to the product tenacity $\mathrm{x}$ elongation as determined by HVI in order to detect possible drifts of the HVI tensile measurements. The authors are also emphasizing the importance of measuring the work of rupture when evaluating the potential textile performance of fibres. Work of rupture, a function of tenacity and elongation, indicates the amount of energy that would be necessary to break a bundle of fibres. This study suggests breeders should work to improve fibre elongation in their programmes because the data indicate that improving fibre tenacity while ignoring fibre elongation may inhibit the ability to increase work to rupture values (Fig. 6).

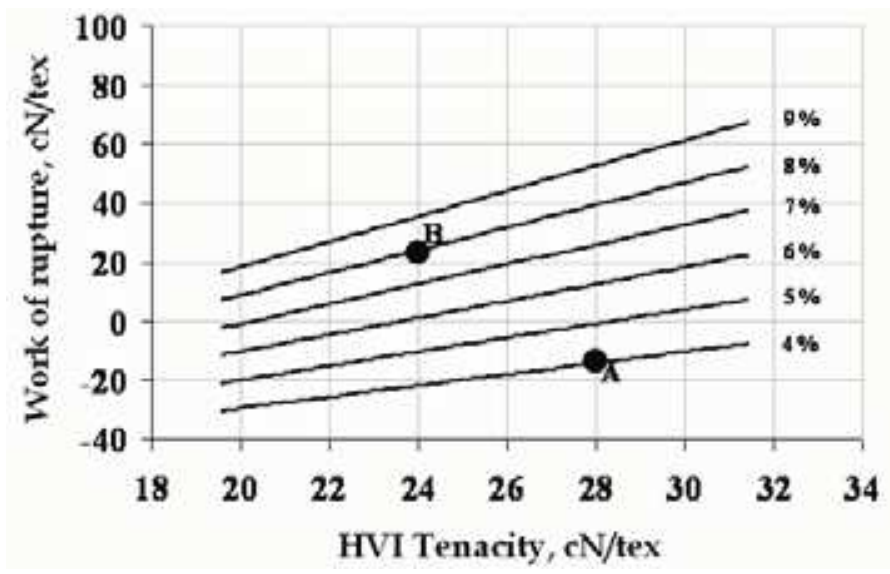

Fig. 6. Percentage change of work of rupture vs. HVI tenacity (Benzina \& al., 2007) Variety A: $28 \mathrm{cN} /$ tex, $4 \%$ elongation; Variety B: $24 \mathrm{cN} /$ tex, $8 \%$ elongation Variety B would perform better in spinning and weaving than variety A

\subsection{Single fibre testing}

In investigating the influence of the microstructure of synthetic fibres on the physicomechanical properties, micro-stress equipment has been found to be very useful (Isings, 1964). Although results obtained for fibres of relatively regular cross section are more simply interpreted than those for fibres with less regular cross section, e.g., cotton, useful data can be obtained in the latter cases also. The breakage of a single fibre is considered as one of the recent tools to understand this relationship between the mechanical behaviour and the fine microstructure of fibres.

\subsubsection{Tensile and fatigue tester}

Today Favimat (Textechno Herbert Stein GmbH and Co.KG, Germany) and Mantis (Zellweger-Uster, Charlotte, NC) testing determine the traditional single fibre data, the 
tensile strength and the elongation at a constant rate of extension. The Favimat testing instrument allows to obtain additional fibre parameters such as capturing fibre crimps, tenacity, linear density, and work to rupture. Parameters measured with the Mantis were the breaking load or force to break, $\mathrm{Tb}(\mathrm{g})$, and the fibre ribbon width, $\mathrm{RW}(\mu \mathrm{m})$.

Another strength tester, which was used mainly in research domain of man made fibre, is the Universal Fibre Testing Machine (UFT). This apparatus was developed by Bunsell and al. (Bunsell \& al., 1971) at the beginning of the 1970s. The UFT allows to carry out the testing of single fibres in tension, creep, relaxation and fatigue. Early research (Bunsell \& Hearle, 1971) carried out, on PA 6.6 fibres, using UFT and scanning electron microscope have showed a distinctive tensile fatigue process. Since then, this machine has been greatly used to highlight the behaviour in fatigue of thermoplastic fibres (Oudet \& Bunsell, 1987; Ramirez \& Bunsell, 2006; Elamri \& Lallam, 2007), aramid fibres (Lafitte \& Bunsell, 1985) and carbon fibres (Bunsell \& Somer, 1992). The technique of mounting the individual fibre in the testing machine was described in the handbook of the tensile properties of textile and technical fibres (Bunsell, 2009). Based on a variety of testing procedures, the results suggest that the UFT appears satisfactory for measuring current and future cotton properties.

\subsubsection{Tensile failure}

The authors of this chapter have used this machine to bring out the single cotton fibre breakage with both tensile and fatigue testing. The simple tensile test is carried out by setting a constant deformation rate of $20 \mathrm{~mm} / \mathrm{min}$ under a pre-tension of $0.2 \mathrm{cN} /$ tex to avoid the crimp. The deformation rate used is often adjusted to result in fibre failure after approximately 20 seconds. The fatigue tests are realised by imposing a sinusoidal load using a vibrating pot and controlling the amplitude of the maximum and minimum load at a determined frequency.

As regards to the tensile results, authors revealed that there are good correlations between single-fibre strength and bundle strength, measured by the HVI, of cotton fibres (Harzallah $\&$ al., 2010). These results are also in agreement with Thibodeaux and al. results (Thibodeaux \& al., 1998). These points make the evaluation of bundle strength more beneficial to predict the strength of the yarn. Basically, the yarn strength is determined not only by fibre strength, but also by fibre-to-fibre interactions as induced by length, friction and degree of twist. On the other hand, in order to elucidate the fundamental problem of the bundle fibre tests by understanding the fundamental nature of fibre fracture under stress. Hearle and al. (Hearle \& al., 1998) presents, in his book, different shapes of failure and classify them into categories. This classification is based on a combination of the fracture appearance examination, the microscopic cause, and the structural mechanism.

The fibre fracture of cotton fiber after tensile and fatigue testing were discussed in previous works (Benzina \& al., 2007; Harzallah \& al., 2010). In these works, two types of cotton have been chosen. Cotton I is very coarse with low tenacity $(20.6 \mathrm{cN} /$ tex $)$, while cotton II is fine and has a high tenacity (36.4 cN/tex). The electron micrographs (Figures $7 \mathrm{a}$ and $7 \mathrm{~b}$ ) of individual fibres taken under tension show that the reversal area tends to untwist in order to elongate the fibre; this generates stresses that can cause an axial splitting between the frills. The split runs around the fibre until it reaches the line of weakness and then breaks. Meredith (Meredith, 1951) explained that the uneven exterior of a dry cotton fibre's structure contains parallel wrinkles at a slight angle to its axis, forming a helical structure directly related to fibre reversals and twists. These reversals are related to the orientation of secondary walls and represent areas of variation in breaking strength. The adjacent reversal areas are constricted and are less dense which is the weak point (Hsieh, 1999). 


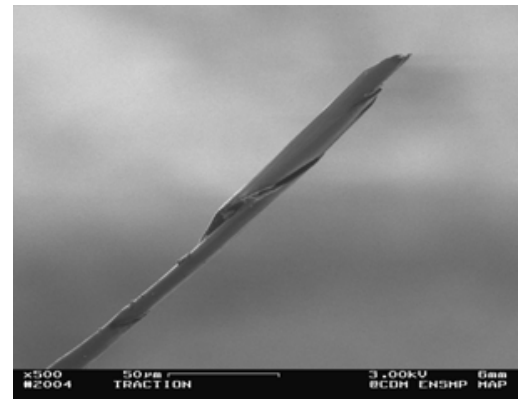

Fig. 7a. Elongated fibre during the tensile test (cotton III)

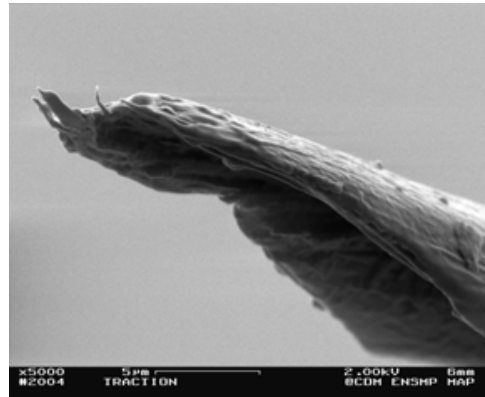

Fig. 7b. Morphology of fibre after tensile test (cotton III)

\subsubsection{Fatigue failure}

Harzallah and co-workers (Drean \& al., 2005; Benzina \& al., 2007; Harzallah \& al., 2010) have conducted experiments to understand the fatigue mechanisms of cotton fibre. These experiments have shown that under cycling loading conditions, approximately 50 to $70 \%$ of the breaking load, the fibrils are axially oriented (Fig. 8b) at the reversal point of the fibre. This generates an area of high stress concentration inducing a separation of fibrils adjacent to this point before failure. The failure of macro-fibrils seems to be the mechanism precursor to the initiation and propagation of a crack. The rupture of macro-fibrils is initiated by a defect while applying the fatigue solicitation in the fibre.

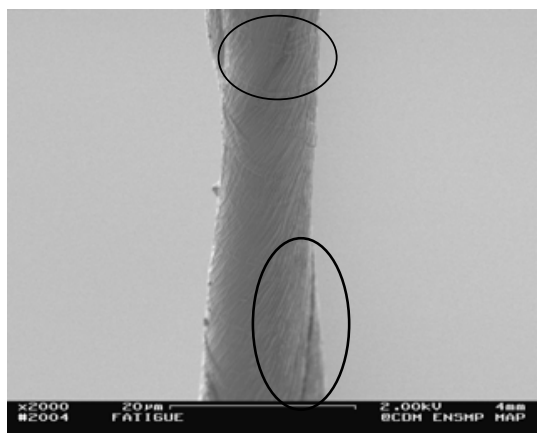

Fig. 8a. Before the fatigue test (cotton I) 


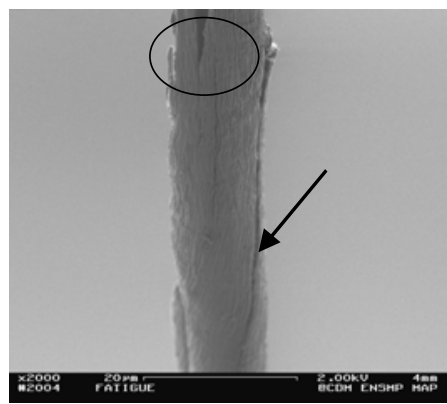

Fig. 8 b. After the fatigue test (cotton I)

The crack begins at the fibre surface (Fig. 8a) and progresses continuously up to the rupture (Fig. $8 \mathrm{~b}$ ). The crack zone appears as a small cut on the fibre surface, making a small angle with the axis of the fibre (Fig. 8a). The crack propagates along the external layers of the fibre and the length of this crack reached several times the fibre perimeter (Fig. 9). Subsequently, the section can no longer bear the load and the crack suddenly propagates into the core until the final fracture of the fibre.

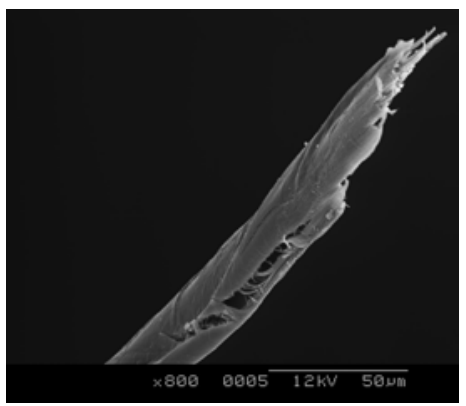

Fig. 9. External cracks after fatigue test (Cotton I)

The ruptured fibre presents two ends (left and right of the rupture). The first end presents both the initiation and propagation of the longitudinal crack (Fig. 9). The other end does not present the initiation and propagation but shows a fracture appearance with small inwardly curved tapes (Fig. 10a). This phenomenon highlights that prominent stresses are induced on the fibre surface instead of within the fibre core.

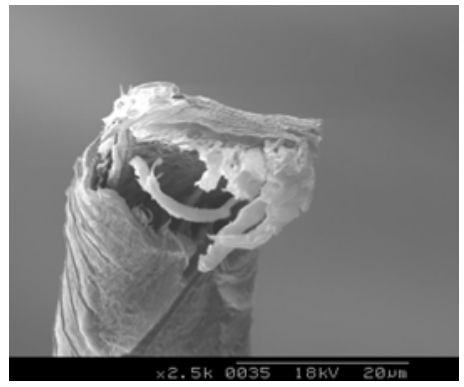

Fig. 10a. Thick package of micro-fibrils (cotton I) 


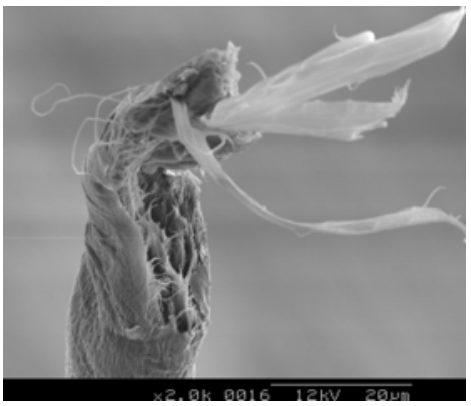

Fig. 10b. Thin package of micro-fibrils (Cotton III)

As far as cotton maturity is concerned, the high maturity of cotton I fibre has induced a lower helix angle. Based on previous work (Menachem, 1998), it has been demonstrated that such a lower helix angle increases the stiffness and makes the fibre brittle. This has been confirmed by our observation. The brittleness of cotton I fibre is due to crack propagation. Commonly cotton III presents a low maturity and a high helix angle which induces a less brittle fibre allowing the whole fibre structure to work under stresses. Considering the fracture appearance of cotton III (Fig. 11), it can be noticed that the whole microfibrils have contributed to the mechanical properties of the fibre. In this case, no surface defects have been observed on the fibre surface which avoids the cracks initiation and propagation. Compared to cotton I, it can be noticed that the stresses due to loading are more uniformly spread within the structure of cotton III fibre with a slight stress concentration effect within the fibre core.

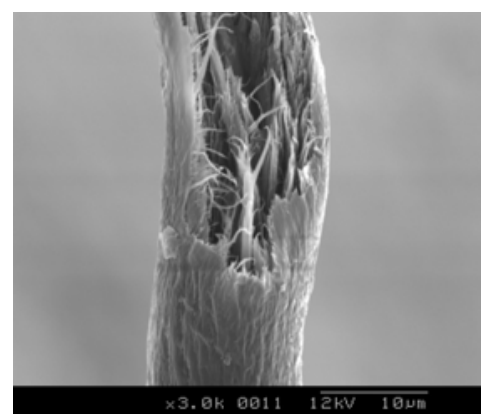

Fig. 10. Wrenching phenomenon for Cotton III

We can also observe for the two types of cotton that the package of fibrils are more or less important depending on the fibre maturity as shown on the following electron micrographs (Figs. 9a and 9b). Actually, these figures show that very mature cottons tend to have thick packages of micro-fibrils while less mature fibres tend to have thinner packages. According to these results and micrographs, we can suppose the existence of two modes of failure depending on cotton maturity.

\section{Surface characterisation}

As described previously, cotton fibres are a very complex material due to their particular structure and morphology. Thus, in order to enhance the performances of cotton based materials and fabrics, it is necessary to carefully analyse the surface properties of cotton 
fibres. Many investigation techniques are available to observe or to characterise the fibres' surface depending on the observation scale. The following techniques can be quoted: Scanning electron microscope (SEM), which can produce very high-resolution images of a sample surface; Transmission electron microscopy (TEM), which allows the observation of ultra-thin specimen; Atomic Force Microscope (AFM), which is a very high-resolution type of scanning probe microscopy, with a resolution on the order of fractions of a nanometer; Electron Spectroscopy for Chemical Analysis (ESCA), which is a very outstanding tool to characterize the polymers surface up to 10nm depth (Cheetham \& Day, 1987; Prutton, 1994); Infra-Red and Raman Spectroscopy, which is nowadays a very common tool for the chemical and physical characterisation of surfaces (Siesler \& Holland-Moritz, 1980); Inverse Gas Chromatography (ICG) to determine the thermodynamic surface properties and some morphological aspect of fibres. In the following paragraphs, the SEM, AFM and ICG techniques will be described as tools to evaluate the surface characteristics of cotton fibres before and after chemical treatment.

\subsection{SEM observation}

The sample's image is generated by scanning it with a high-energy beam of electrons in a raster scan pattern. The interaction between electrons and the atoms constituting the sample produces signals that contain information related to the sample's surface topography and composition. The main signals produced by SEM are secondary electrons, back-scattered electrons, characteristic X-rays, light and transmitted electrons. The most common detector in all SEMs consists in secondary electron detectors.

SEM is essentially used for the observation of the fibre surface, fibre breakage and fibre diameter measurement. Hearle \& al en 1970 (Hearle \& Cross, 1970) were the first researchers who to use SEM for the observation of fibre breakage. This technique gives high resolution image, however one of the main disadvantages of SEM in characterization of polymer surface is the surface heating caused by the polymer's non-conductive property. Consequently, fibres need to be made conductive by covering the sample, by means of a sputter coater, with a thin layer of conductive material like gold.

To illustrate this, Drean and co-workers have conducted experiments to understand the evolution of surface characteristics of cotton fibres before and after a chemical treatment (Rjiba \& al, 2007). These experiments have been conducted on different types of raw cotton which have been treated by soxhlet ethanol extraction performed for 6 hours with hot $95 \%$ ethanol to remove sugars, mineral, non-cellulosic and organic maters as well as wax and pectic maters. The figures $11 \mathrm{a}$ and $11 \mathrm{~b}$ illustrate the results. It can be noticed that the raw cotton fibre presents thin scratches that are the result of the treatment making the fibre pores more attainable.

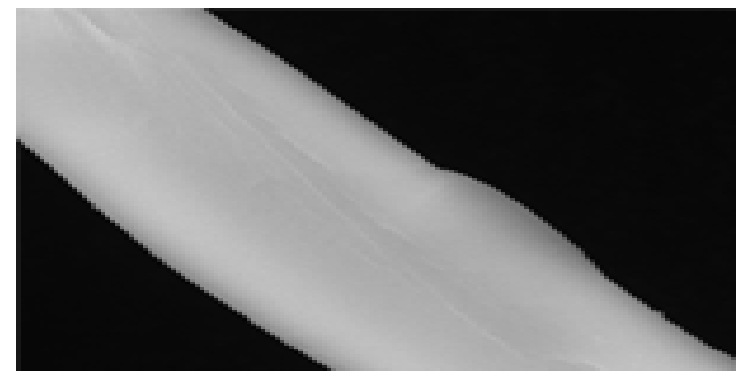

Fig. 11a. SEM observation for raw C21 cotton fibre (X 5000) 


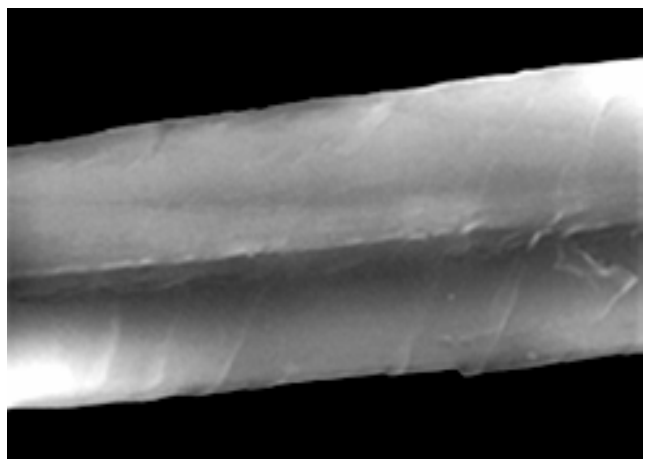

Fig. 11b. SEM observation for ethanol treated C21 cotton fibre (X 5000)

\subsection{AFM observation}

As mentioned above, Atomic Force Microscope (AFM) is a very high-resolution type of scanning probe microscopy, with a resolution on the order of fractions of a nanometer. The AFM is composed of a cantilever with a sharp tip at its end which is used to scan the specimen surface (Figure 12). When the tip is in the vicinity of a sample surface, forces between the tip and the sample induce a bending of the cantilever. Theses forces can be van der Waals forces, capillary forces, chemical bonding, electrostatic forces... The cantilever deflection is measured with the help of laser beam which is reflected from the surface of the cantilever to a photodetector. Usually, the sample is placed on a piezoelectric tube which can move the sample in $x$ and $y$ directions for scanning the sample and in $z$ direction for maintaining a constant force.
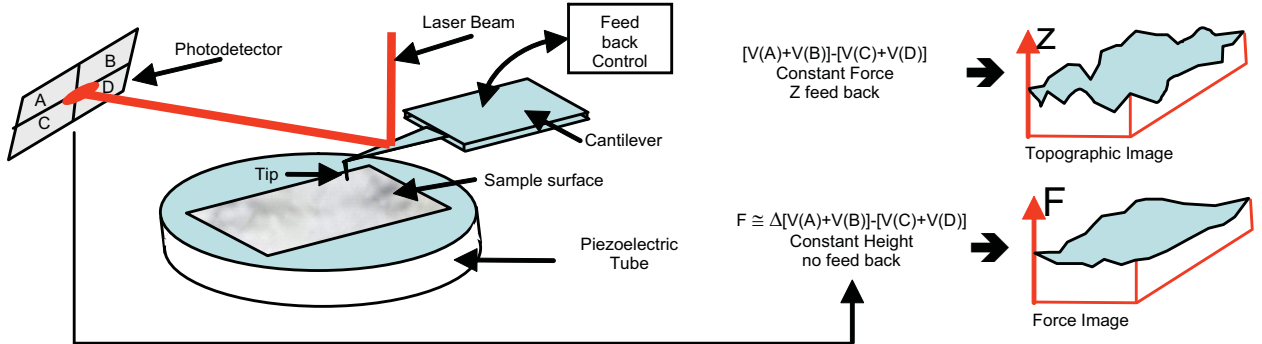

Fig. 12. Atomic Force Microscope block diagram

Three main operating modes are available for imaging the surface: the contact mode, the non-contact mode and the tapping mode. Contact mode can be used when all forces are repulsive and the operation mode consists in maintaining a constant force between surface and tip during the surface scanning by keeping the cantilever deflection constant. In noncontact mode, the cantilever oscillates at a frequency a little higher than its resonant frequency. The van der Waals forces on the surface lead to decrease the cantilever resonance frequency. The feed back control then adjusts the tip to sample distance to maintain a constant cantilever frequency. Based on the data collected at each $(x, y)$ point, a topographic image of the sample surface can be reconstructed. In tapping mode imaging is implemented in ambient air by oscillating the cantilever at a frequency close to the cantilever's resonant 
frequency using a piezoelectric crystal. During scanning, the tip vertically oscillates and alternately contacts the surface and lifts off. A tapping AFM image is then completed by imaging the force of the intermittent contacts of the tip with the sample surface.

AFM is a very well adapted tool to image the topography of the surface as well as to calculate the surface roughness. In our case, the surface roughness is defined as Ra parameter which is the mean value of overall y ordinate of the analyzed profile for a given length.

The cottons previously observed with the help of SEM (raw and soxhlet ethanol extracted cottons) have been characterised by means of a Digital Instrument DI-3000 AFM. The cotton fibres have been stuck on a stainless steel plate and then scanned in tapping mode. Such an experiment is quite difficult to carry out because of the fibre vibration during the scan. The experiments have been carried out on a $250 \mathrm{~nm}^{2}$ surface at a $1 \mathrm{~Hz}$ frequency. The $5 \mu \mathrm{m}^{2}$ AFM images of $\mathrm{C} 17$ cotton are given in figures. 13. It can be noticed in figure 13a that in case of raw fibre, the fibrils are visible and well parallel organised. After treatment, figure $13 \mathrm{~b}$, a surface modification can be highlighted; the fibrils are less parallel and the surface seems to be less rough.

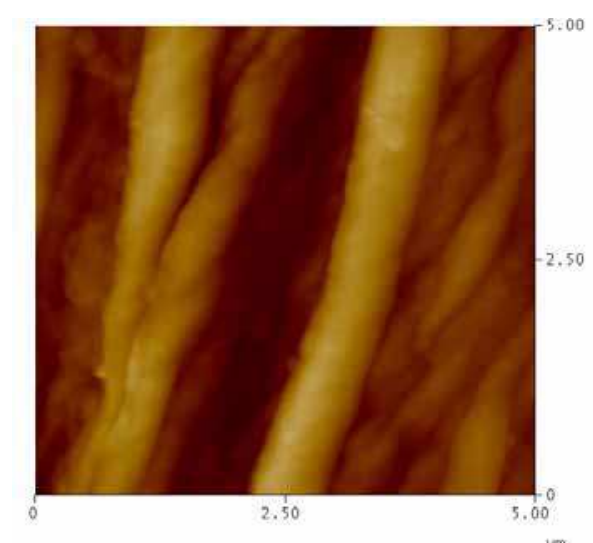

Fig. 13a. AFM observation for raw C17 cotton fibre $\left(5 \mu \mathrm{m}^{2}\right)$

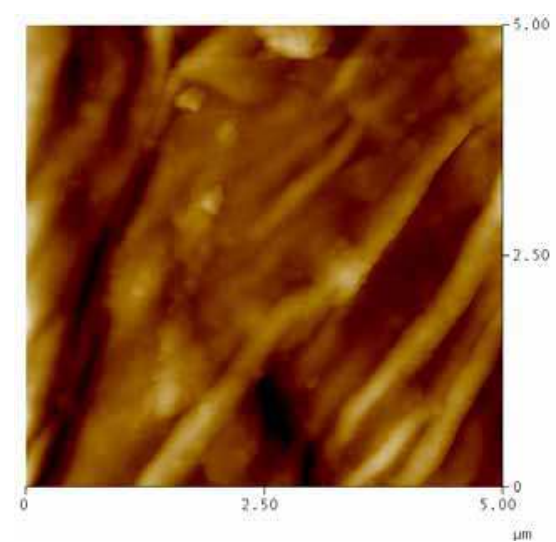

Fig. 13b. AFM observation for ethanol treated C17 cotton fibre $\left(5 \mu \mathrm{m}^{2}\right)$ 
Figures 14 give an example of an AFM profile for C17 cotton. From the profiles obtained by scanning, the Ra value can be calculated. At $5 \mu \mathrm{m}$ scale, Ra values are respectively 67.2 and 49.4 for raw and ethanol extracted fibres and at $2 \mu \mathrm{m}$ scale, Ra values are respectively 26.2 and 23.0 for raw and ethanol extracted fibres. These results confirm the observation given by AFM images Figures 13a and $b$ and corroborate the dependence between cotton surface characteristics and quantity of foreign matter at the surface of the fibre.

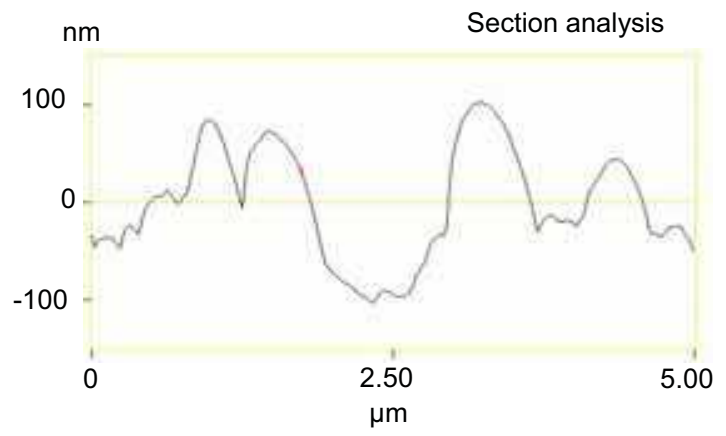

Fig. 14a. AFM roughness profile for raw C17 cotton fibre

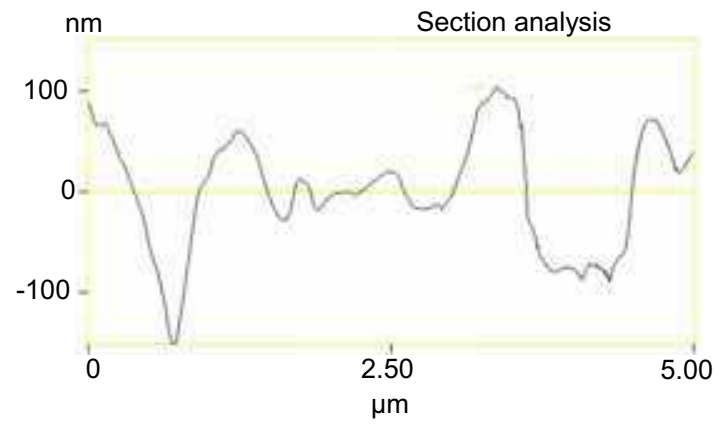

Fig. 14b. AFM roughness profile for ethanol treated C17 cotton fibre

\subsection{Inverse gas chromatography surface characterisation}

Inverse gas chromatography (IGC) is a very sensitive gas phase technique developed to study the surface properties of particles and fibrous materials. In IGC the roles of solid and gas are inverted compared to classical analytical gas chromatography. In IGC, a column filled with the solid sample to be investigation and a single gas (probe molecule) is injected. The aim of this characterisation technique is to determine the thermodynamic surface properties and surface morphological aspect of cotton fibre. The surface characterisation by Inverse Gas Chromatography (IGC) has been recommended by several papers (Papirer \& al., 2000; Santos \& al., 2001). This method is based on the analysis of gaseous probe adsorption on a solid surface to determine the dispersive component $\gamma_{S}^{D}$ of the surface energy. 


\subsubsection{Theoretical aspects of inverse gas chromatography}

IGC, under "infinite dilution" conditions, i.e very high dilution of the probe into the carrier gas (helium), permits the determination of both dispersive and polar surface properties of a solid. The dispersive component $\gamma_{S}^{D}$ of the surface energy of cotton fibres is calculated from the retention times $\left(t_{R}\right)$ of a series of $n$-alkanes injected into the column containing the fibres. From $t_{R}$, the following quantities can be calculated:

$$
\begin{aligned}
V_{N} & =D_{c}\left(t_{R}-t_{0}\right) \\
\Delta G_{a} & =-R T \ln \left(V_{N}\right)
\end{aligned}
$$

where $V_{N}$ is the retention volume, $t_{0}$ is the retention time of a probe that is not adsorbed on the cotton, $\mathrm{D}_{\mathrm{c}}$ is the helium flow rate, and $\mathrm{T}$ is the absolute temperature at which the measurement is carried out. $\Delta G_{a}$ is the standard variation of the free energy of adsorption. Then, according to Dorris and Gray (Dorris \& Gray, 1980), the dispersive component $\gamma_{S}^{D}$ of the surface energy is then given by the following equation:

$$
\gamma_{S}^{D}=\frac{1}{4 \gamma_{\mathrm{CH}_{2}}}\left(\frac{\Delta G_{a}\left(\mathrm{CH}_{2}\right)}{N \cdot a_{\mathrm{CH}_{2}}}\right)^{2}
$$

where $\gamma_{\mathrm{CH}_{2}} \approx 36,5 \mathrm{~mJ} / \mathrm{m}^{2}$ at $20^{\circ} \mathrm{C}, \mathrm{N}$ is Avogrado's number and $\mathrm{a}_{\mathrm{CH} 2}$ (cross-sectional area of an adsorbed $\mathrm{CH}_{2}$ group) $\approx 6 \AA^{2}$.

From IGC measurements, based on the comparison of the retention times $t_{\mathrm{N}}$ of linear $\mathrm{n}$ alkanes and of branched and/or cyclic alkanes, a morphological parameter $(\chi)$ has been recently defined. Then, an index of morphology of the cotton fibre surface can be defined (Rjiba \& al., 2007; Rjiba \& al., 2010) as follows:

$$
I M \chi_{T}=100 \times \frac{\left(\chi_{\exp }-\chi_{T}\right)}{\chi_{T}}=100 \times \frac{\Delta_{T}}{\chi_{T}}
$$

\subsubsection{ICG experimental characterisation}

The experiments are carried out on different types of cotton fibres and as an example C17 cotton has been chosen. This cotton from Senegal has a wax content of $0.5 \%$ and a maturity ratio $\mathrm{MR}=0.818$. Two types of fibres have been tested, raw material and soxhlet ethanol extracted fibres (extraction performed for 6 hours with hot $95 \%$ ethanol). The main problem of the experiment is the preparation of the column. In fact, IGC is carried out in good conditions if the filling of the column is homogeneous.

A specific column filling technique has been developed. With the help of microspinning facilities of CIRAD (French Agricultural Research Center for International Development) cotton fibres have been spun in sliver then drawn into rowing. Then, these $2.8 \mathrm{~g} / \mathrm{m}$ rowings have been twisted and introduced into the column. This preparation leads to a homogeneous packing into the chromatography column.

Chromatograms were obtained with a Varian 3800 programmable gas chromatography equipped with a flame ionization detector; helium was used as the carrier gas and n-alkanes as probes. As a result, the variation of the dispersive component $\gamma_{S}^{D}$ of the surface energy of C17 cotton fibre as a function of temperature is shown figure 15. 


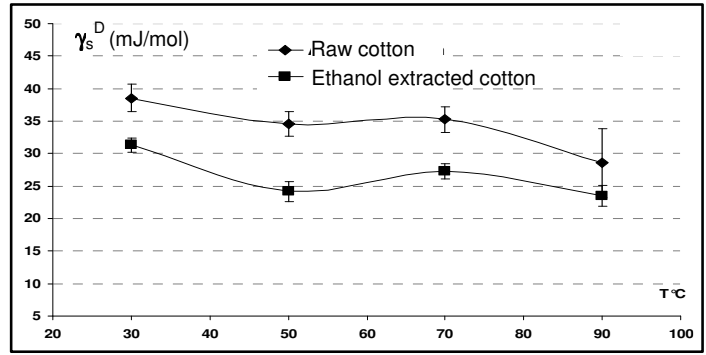

Fig. 15. Variation of $\gamma_{S}^{D}$ vs. temperature

It can be noticed that the values of $\gamma_{S}^{D}$ of extracted cotton fibres are lower than raw cotton fibres. This result highlights that the waxes play a key role on surface energy of cotton fibres. Moreover, $\gamma_{S}^{D}$ decreases with the temperature, decrease related to thermal dilatation of the fibres.

The calculation of $I M \chi_{T}$ (Rjiba \& al., 2010) for extracted cotton fibres gives a value close to zero. This result shows that the cotton fibre surface after extraction is very smooth and homogeneous from a morphological point of view.

Such an example clearly demonstrates that IGC is a very convenient technique to determine the surface properties of cotton fibres.

\section{Acknowledgments}

We would like to thanks Dr. Eric Hequet - FBRI, Lubbock, Texas, USA - and his team for their kind help in carrying out specific experiments.

\section{References}

ASTM D1769-77. (1984). Standard Test Method for Linear Density of Cotton Fibers (Array Sample), Annual Book of ASTM Standards. Vol. 07.02, 389-392, Philadelphia, PA

ASTM D1445-75. (1984). Standard Test Method for Breaking Strength and Elongation of Cotton Fibres (Flat bundle Method). Annual Book of ASTM Standards, 330- 339, Philadelphia, PA, 1984.

ASTM D1447-83. (1984). Standard Test Method for Length and Length Uniformity of Cotton Fibers by Fibrograph Measurement, Annual Book of ASTM Standards, Vol. 07.02, 340-346, Philadelphia, PA.

ASTM D1448-84. (1984). Standard Test Method for Micronaire Reading of Cotton Fibers, Annual Book of ASTM Standards, Vol. 07.02, 347-350, Philadelphia, PA.

ASTM D1464-79. (1984). Standard Test Method for Differential Dyeing Behaviour of Cotton, Annual Book of ASTM Standards, Vol. 07.02, 351-353, Philadelphia, PA.

ASTM D 4605-86. (1994). Standard Test Methods for Measurement of Cotton Fibres by High Volume instruments (HVI). Annual Book of ASTM Standards, Vol. 07.02, 486-494, Philadelphia, PA.

Annis, P.A.; Quigley, T.W.Jr. \& Kyllo, K.E. (1992). Useful Techniques in Textile Microscopy, I AATCC, 24(8), 19-22. 
Beasley, C.A. (1975). Developmental morphology of cotton flowers and seed as seen with the scanning electron microscope, American eburnal of Botany, 62(6), 584-592

Benzina, H.; Harzallah, O. \& Drean, J.Y. (2007). Morphological study of the cotton by specifying the breakage of a single fiber, The Fiber Society Conference, May 23-25, Greenville - South Carolina.

Benzina, H.; Hequet, E.; Abidi, N.; Gannaway, J.; Drean, J.Y. \& Harzallah, O. (2007). Using Fiber Elongation to Improve Genetic Screening in Cotton Breeding Programs, Textile Research eburnal, 77(10), 770-778.

Boylston, E.K.; Evans, J.P. \& Thibodeaux, D.P. (1995). A Quick Embedding Method for Light Microscopy and Image Analysis of Cotton fibres, el Biotech. Histochem., 70(1), 24-27.

Bragg, C.K. \& Shofner, F.M. (1993). Rapid direct measurement of short fibre content, Textile Research eburnal, 63(3), 171-176.

Brown, R.M.J.; Saxena, I.M.; \& Kudlicka, K. (1996). Cellulose biosynthesis in higher plants, Trends in plant science, 1, 149-156.

Bunsell, A.R.; Hearle, J.W.S.; \& Hunter, R.D. (1971). An apparatus for fatigue-testing of fibres, el Phys. E. Sc. Instrum., 4, 868-872.

Bunsell, A.R.; \& Hearle, J.W.S.; (1971). A mechanism of Fatigue Failure in Nylon Fibres, cburnal of Materials Science., 6, 1303-1311.

Bunsell, A.R.; \& Somer, A.; (1992). Plastics, Rubber \& Comp, Processing and Applications, 18, 263-267.

Bunsell, A.R.; (2009). Handbook of tensile properties af textile and technical fibres, Woodhead Publishing Limited, ISBN 978-1-84569-387-9, Cambridge, U.K.

Cheetham. A.K.; \& Day. P., (1987). X-ray Photoelectron Spectroscopy and Related Methods, in Solid State Chemistry Techniques, Oxford University Press: New York. 1987, 84120.

Dorris, G.M. \& Gray, D.G. (1980). Adsorption of $n$-alkanes at zero surface coverage on cellulose paper and wood fibers, eburnal of Colloid and Interface Science, 77, 353-362

Drean, J.Y.; Benzina, H. \& Harzallah, O.; (2005). Fine Study of Cotton Fiber: Methodology and Feasibility, Beltwide Cotton Conference, New Orleans (Louisiana-USA), 230723011; 4-7 janvier 2005.

Elamri, A.; Lallam, A.; Harzallah, O. \& Bencheikh, L. (2007). Mechanical characterization of melt spun fibers from recycled and virgin PET blends, cburnal of Materials Science, $42,8271-8278$.

Goldthwait, C.F.; Smith, H.O. \& Barnett, M.P. (1947). New dye technique shows maturity of cotton, Textile World, July issue, 105-110.

Harzallah, O.; Benzina, H. \& Drean, J.Y. (2010). Physical and mechanical properties of cotton fibres: Single-fiber failure, Textile Research eburnal, 80(11), 1093-1102.

Hearle, J.W.S.; Cross, P.M.; (1970). The fractography of thermoplastic textile fibers, eburnal of Materials Science, 5, 507-516.

Hearle, J.W.S.; An atlas of fiber fracture, Textile Manufacturer, 100, no.1177, 1973, p 24-25.

Hearle, J.W.S.; Lomas, B.; Bunsell, A.R.; 1974)The study of fiber fracture, Applied Polymer Symposia, , no.23, p 147-156.

Hearle, J.W.S.; Lomas, B. \& Cooke, W.D. (1998). Atlas of fibre fracture and damage to textiles, Second edition, Woodhead Publishing Limited, ISBN 1-85573-319-6, 1998.

Hertel, K.L. (1940). A method of fibre length analysis using the fibrograph, Textile Research dburnal, 10(12), 510-525. 
Hertel, K.L. (1953). Fibre strength and extensibility as measured by stelometer, Cotton Research Clinic report, National Cotton Council, 18-25.

Hsieh, Y. (1999). Structural development of cotton and linkages to fibre quality.In: Cotton fibres development biology, Quality Improvement, and Textile Processing, A. Basra (ed). pp.167-183, Food Product Press, Binghamton, NY,

Huang, Y. \& Xu, B. (2002). Image Analysis for Cotton Fibers, Part I: Longitudinal Measurements, Textile Research eburnal, 72(8), 713-720.

Isings, J. (1964). The Influence of Stress and deformation on the structure of the Cotton Fiber, Textile Research eburnal, 236-246.

Joshi, P.C.; Wadhwani A.M. \& Johri, B.M. (1967). Morphological and embryological studies of Gossypium L., Proc. Nat. Inst. Sci., India 33B

Kohel, R. (1999). Cotton Germplasm Resources and the potential for Improvement Fiber Productivity and Quality, Cotton Fibers, Developmental Biology, Quality Improvement, and Textile Processing. A. Basra Ed., Food Product Press, Binghamton, New York

Kunzek, H.; Kabbaert, R. \& Gloyna, D. (1999). Aspects of material science in food processing: changes in plant cell walls of fruits and vegetables, Z. Lebensm Unters Fersch, A, 208, 233-250.

Lafitte, M.H. \& Bunsell, A.R., (1985). The creep of kevlar-29 fibers, Polymer Engineering \& Science, 25, 182-187.

Lagière R., Le Cotonnier, Maisonneuve \& Larose, Paris, 1966.

Landstreet, C.B.; Waggoner, C.M. \& Guggenheim, G.N. (1989). The mass fibrogram: a method for increased precision in measuring short fiber content and uniformity ratios with scanning instruments, Beltwide Cotton Conference, January 2-7, Nashville, TE, National Cotton Council of America, 610-612.

Lawson, R.; Ramey, H.H.Jr.; \& krowicki, R.S. (1976) Cotton Fibre Tenacity and Elongation in Rapidly Changing Humidity, Textile Research eburnal, 46,715-719.

Lewin, M. \& Pearce E.M. (1998). Handbook of Fibre Chemistry, 2nd ed., Marcell Dekker. New York

Lord, E. (1956). Relation between different measures of maturity and fineness of cotton, eburnal of the Textile Institute, 47, 209-221.

Menachem, L. (1998). Handbook of Fibre Chemistry, second edition, Marcel Dekker, ISBN 08247-9471-0, New York

Meredith, R. (1951). Cotton Fiber Tensile Strength and X-ray Orientation, eburnal of the Textile Institute, 42, T291-T299.

Morton, W.E. \& Hearle, J.W.S. (1975) Physical properties of textile fibres, 2nd edition, The Textile Institute, ISBN 1-870812-41-7, London, England.

Morton, W.E. \& Hearle, J.W.S. (2008), Physical properties of textile fibres, 4th edition, Woodhead Publishing Limited, ISBN 978-1-84569-220-9, Cambridge, England.

Oudet, CH. \& Bunsell, A.R. (1987). Effects of structure on the tensile, creep and fatigue properties of polyester fibres, eburnal of Materials Science, 22(2), 4292-4298.

Papirer, E.; Brendle, E.; Balard, H.; Vergelati, C. (2000). Inverse gas chromatography investigation of the surface properties of cellulose, Journal of Adhesion Science and Technology, 14, 321-337

Parry, G. (1982). Le cotonnier et ses produits : origine et constitution, Maisonneuve \& Larose , coll. Techniques agricoles et productions tropicales, Paris V, 
Powland, S.P.; Nelson, M.L.; Welch, C.M. \& Hebert, J.J. (1976) Cotton fibre morphology and textile performance properties, Textile Research cburnal, 46, 194-214.

Pressley, E.H. (1942). A cotton fibre strength tester, ASTM bulletin, 10, 13-17.

Prutton, M., (1994). Introduction to Surface Physics.1994: Oxford University Press.

Raes, A.T.J. \& Verschraege, L. (1981). A consideration of the real maturity of cotton fibres, cburnal of the Textile Institute, 72, 191-200.

Rjiba, N.; Nardin, M.; Drean, J.-Y. \& Frydrych, R. (2007). A study of the surface properties of cotton fibers by inverse gas chromatography, eburnal of Colloid and Interface Science, 314, 373-380

Rjiba, N.; Nardin, M.; Drean, J.-Y.; Frydrych, R. (2010). Comparison of surfaces properties of different types of cotton by inverse gas chromatography, eburnal of Polymer Research, $17,25-32$

Roberty, G. (1949). Variation de longueur dans les poils d'une même graine de coton, Coton et Fibres Tropicales, 4(1), 25-32

Santos, J; Gil, MH; Portugal, A; Guthrie, JT. (2001). Characterisation of the Surface of a Cellulosic Multi-Purpose Office Paper by Inverse Gas Chromatography, Cellulose Communications, (8), 217-224

Seagull, R. \& Alspaugh, P. (2001). Cotton fibre development and processing. Cotton Incorporated, International Textile Center, Texas Tech University, Lubbock - Texas, USA

Shenai, V. (1988). Technology of Mercerizing. Part 10: Cotton fibres, Textile Dyer Print, 21(2), 25-29.

Siesler, H.W. \& Holland-Moritz K., (1980) Infrared and Raman Spectroscopy of Polymers, 1980, 389 p, M.Dekker, New-York

Stewart, J.M. (1975). Fibre initiation on the cotton ovule (Gossypium hirsutum), American eburnal of Botany, 62(7), 723-730

Taylor, R.A. (1986). Cotton Tenacity Measurements with High Speed Instruments, Textile Research eburnal, 56, 86-94 (1986).

Taylor, R.A.; Brown, R.S. \& Godbey, L.C. (1991). Reducing HVI strength variability by sensing humidity, Beltwide Cotton Conferences.

Thibodeaux, D.P. \& Evans, J.P. (1986). Cotton fibre maturity by image analysis, Textile Research eburnal, 56, 130-139.

Thibodeaux, D.P.; Herbert, J.J.; Abd El-Gawad, S. \& Moraitis, J.S. (1998). Quality measurements-relating bundle strength to mantis single fibre strength measurements, The eburnal of Cotton Science, 2, 62-67.

Thibodeaux, D.P. \& Rajasekaran, K. (1999). Development of New Reference Standards for Cotton Fibre Maturity. The eburnal of Cotton Science, 3, 188-193

Waterkeyn, L. (1987). Light microscopy of the cotton fibre, Cotton fibres : their development and properties, A technical monograph from the Belgian Cotton Research Group. International Institute for Cotton, Manchester, U.K.

Xu, B.; Pourdeyhimi, B. \& Sobus J. (1992). Charaterization of fibre crimp by image analysis: definition, algorithms and techniques, Textile Research eburnal, 62, 73-80.

$\mathrm{Xu}$, B.; Pourdeyhimi, B. \& Sobus, J. (1993). Fibre cross-sectional shape analysis using imaging processing techniques, Textile Research eburnal, 63, 717-730.

Xu, B. \& Pourdeyhimi, B. (1994). Evaluating maturity of cotton fibres using image analysis: Definition and Algorithm, Textile Research eburnal, 64(6), 330-335. 
Xu, B. \& Huang Y. (2004). Image Analysis for Cotton Fibers Part II: Cross-Sectional Measurements, Textile Research eburnal, 74(5), 409-416. 


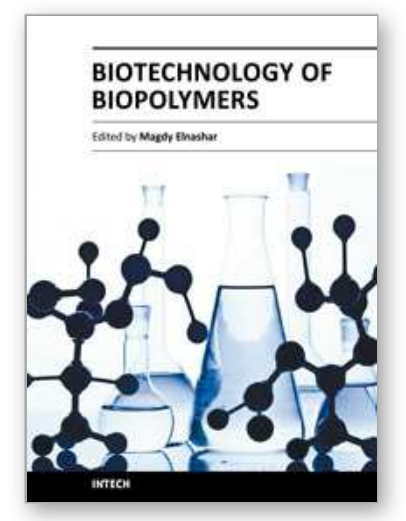

\author{
Biotechnology of Biopolymers \\ Edited by Prof. Magdy Elnashar
}

ISBN 978-953-307-179-4

Hard cover, 364 pages

Publisher InTech

Published online 24, June, 2011

Published in print edition June, 2011

The book "Biotechnology of Biopolymers" comprises 17 chapters covering occurrence, synthesis, isolation and production, properties and applications, biodegradation and modification, the relevant analysis methods to reveal the structures and properties of biopolymers and a special section on the theoretical, experimental and mathematical models of biopolymers. This book will hopefully be supportive to many scientists, physicians, pharmaceutics, engineers and other experts in a wide variety of different disciplines, in academia and in industry. It may not only support research and development but may be also suitable for teaching. Publishing of this book was achieved by choosing authors of the individual chapters for their recognized expertise and for their excellent contributions to the various fields of research.

\title{
How to reference
}

In order to correctly reference this scholarly work, feel free to copy and paste the following:

Omar Harzallah and Jean-Yves Drean (2011). Macro and Micro Characterization of Biopolymers: Case of Cotton Fibre, Biotechnology of Biopolymers, Prof. Magdy Elnashar (Ed.), ISBN: 978-953-307-179-4, InTech, Available from: http://www.intechopen.com/books/biotechnology-of-biopolymers/macro-and-microcharacterization-of-biopolymers-case-of-cotton-fibre

\section{INTECH}

open science | open minds

\section{InTech Europe}

University Campus STeP Ri

Slavka Krautzeka 83/A

51000 Rijeka, Croatia

Phone: +385 (51) 770447

Fax: +385 (51) 686166

www.intechopen.com

\section{InTech China}

Unit 405, Office Block, Hotel Equatorial Shanghai

No.65, Yan An Road (West), Shanghai, 200040, China

中国上海市延安西路65号上海国际贵都大饭店办公楼 405 单元

Phone: +86-21-62489820

Fax: +86-21-62489821 
(C) 2011 The Author(s). Licensee IntechOpen. This chapter is distributed under the terms of the Creative Commons Attribution-NonCommercialShareAlike-3.0 License, which permits use, distribution and reproduction for non-commercial purposes, provided the original is properly cited and derivative works building on this content are distributed under the same license. 